\title{
Teenage girls' experience of the determinants of physical activity promotion: A theory-based qualitative content analysis
}

Mahboobe Borhani ${ }^{1}$, Roya Sadeghi ${ }^{2}$, Davoud Shojaeizadeh ${ }^{3}$, Tayebeh Fasihi Harandi ${ }^{4}$, Mohammad Ali Vakili ${ }^{5}$

${ }^{1}$ Ph.D. Candidate of Health Education \& Health Promotion, Department of Health Promotion and Education, Faculty of Health, Tehran University of Medical Sciences, Tehran, Iran

${ }^{2}$ Ph.D. of Health Promotion, Associate Professor, Department of Health Promotion and Education, Faculty of Health, Tehran University of Medical Sciences, Tehran, Iran

${ }^{3} \mathrm{Ph}$.D. of Health Education, Professor, Department of Health Promotion and Education, Faculty of Health, Tehran University of Medical Sciences, Tehran, Iran

${ }^{4}$ Ph.D. of Health Promotion, Associate Professor, Social Determinants of Health Research Center, Alborz University of Medical Sciences, Karaj, Iran

${ }^{5}$ Ph.D. of Biostatistics, Associate Professor, Department of Biostatistics, School of Medicine, Golestan University of Medical Sciences, Gorgan, Iran

Type of article: Original

\begin{abstract}
Background: The progress of technology in developed countries has changed lifestyles to sedentary and has increased non-communicable diseases. Identifying factors affecting patterns of physical activity among adolescents is valuable and it is important to change these pattern.

Objective: This study aimed to explore teenage girls' experiences regarding the determinants of physical activity promotion based on Pender's Health Promotion Model.

Methods: This qualitative study is a content analysis research on the girls of three high schools in Minoodasht city for six months from September 2015 until the end of February 2016. The data were obtained by focused group discussions and semi-structured in-depth interviews from 48 girls ranging from 15 to 18 years old and six teachers. Data analysis was done using theory-driven qualitative content analysis.

Results: Data analysis resulted in a total number of 53 primary codes which were classified in the six predetermined classifications of Pender's Health Promotion Model (Perceived benefits, perceived barriers, perceived self-efficacy of physical activity behavior, feelings related to physical activity behavior, interpersonal and situational influencers). The results showed that two classifications (perceived barriers, and situational influencers) were considered more important than other classifications in reducing levels of physical activity in adolescent girls and also high self-efficacy for promoting physical activity in adolescents.

Conclusion: The results obtained from this study specified the determinants affecting the promotion of physical activity among adolescent girls and can help the planners to choose the most appropriate methods and strategies in order to promote physical activity among adolescent girls and to prevent chronic non-communicable diseases in this age group and gender.
\end{abstract}

Keywords: Pender's Health Promotion Model, Physical activity, Qualitative study, Teenage girls

\section{Introduction}

Sedentary lifestyle is a major problem in public health. The findings of the World Health Organization show that sedentary lifestyle is one of the 10 leading causes of death around the world (2). Furthermore, this problem compromises a large portion of the economic burden of developing countries, so it is suggested that one should do moderate physical exercise at least 30 minutes a day or preferably 3 days a week (3). Nowadays, one of the most serious public health challenges among teenagers/adolescents, is obesity and lack of mobility. Lack of physical

\section{Corresponding author:}

Associate Professor Dr. Roya Sadeghi, Department of Health Promotion and Education, Faculty of Health, Tehran University of Medical Sciences, Tehran, Iran. Tel: +98.2166954232, Email: sadeghi_roya@yahoo.co.uk Received: December 09, 2016, Accepted: January 30, 2017, Published: August 2017 iThenticate screening: January 25, 2017, English editing: February 10, 2017, Quality control: April 12, 2017 (C) 2017 The Authors. This is an open access article under the terms of the Creative Commons Attribution-NonCommercialNoDerivs License, which permits use and distribution in any medium, provided the original work is properly cited, the use is non-commercial and no modifications or adaptations are made. 
activity is a potential risk factor for cardiovascular disease and obesity, and mortality caused by them. Exercise and mobility are the most important ways to prevent obesity and its consequences (4). Regular physical activity in childhood and adolescence helps to build and maintain a healthy and active life in the future (5). Studies conducted in the field of teenage girls' physical activity indicated a low level of physical activity in this group $(6,7)$. In our society, girls' participation in sports activities is less than boys. Although in recent years, we had a considerable increase in women's participation in sports activities, this rate is not noticeable compared with sports participation for men, considering the female population; so, achieving the desired level of participation of women in sport needs more effort (8). The study of Teimouri et al showed that only $36 \%$ of teenage girls were in the process of adopting physical activity behavior (9). In order to design effective interventions to promote physical activity in this age group and gender, we must recognize the factors affecting physical activity in adolescent girls. Many studies have investigated the determinants of physical activity behavior, but still many physical activity interventions have minimal impact (10). Behavioral changes are often not permanent. So it seems necessary to clarify the barriers and facilitators of physical activity in teenage girls and the promotion of physical activity and educational strategies in them, and qualitative research can be a practical approach to solving the problems in this area (11). The results of these studies can change the attitudes and behavior of teenage girls towards physical activities, and can also help decision makers in designing interventions by providing a deeper understanding of the cultural, social and psychological effects on the behavior and by explaining the barriers and facilitators related to physical activity experience in teenage girls, it may result in reducing the burden of different diseases associated with physical inactivity in this gender and age group. Reviewing the present literature and resources associated with the promotion of physical activity, especially among adolescents, it can be concluded that the vast majority of conducted researches were quantitative studies, and the behavioral pattern of physical activity in each region is related to the cultural, social and climatic conditions of that area; but identifying these factors require regional research. The importance of physical activity and avoiding a sedentary life style among adolescents in Golestan province, have prompted researchers to further consider this issue. So, the present study was designed and implemented to explore the experiences or perceptions of teenage girls in the promotion of their physical activity levels based on Pender's Health Promotion Model.

\section{Material and Methods}

Given that qualitative research can provide better understanding and intervention in the research area, especially in the field of human studies, and since theories or researches about this phenomenon are not perfect and should be more descriptive, the researchers used directed approach in qualitative content analysis. This research was performed through qualitative research method with directed approach on the basis of the Pender's Health Promotion Model analysis. The present study used semi-structured in-depth interviews and 2 focused group discussions to collect data during the six months from September 2015 until the end of February 2016. Subjects included 48 female high school students ranging from 15 to 18 years old who had the experience and knowledge about the phenomenon, and were interested in participating and presenting their experiences in this study. These people were chosen purposefully and with the greatest diversity (in terms of educational field and level of education, age, occupation and education of parents) and continued until data saturation. In addition to students, interviews were also performed with six teachers including 4 physical education teachers and 2 extra curricula teachers from 3 high schools of Minoodasht city. The process of choosing schools, aimed to gain different attitudes in a wide socio-economic spectrum. Individual interviews and focused group discussions were conducted based on the purpose of research. In this study, after collecting data, the theory-driven content analysis method (guided or direct) was used, which was first introduced in 2005 by Hsieh and Shannon (12). Using available theories or studies, the researcher first identified the key concepts or variables and put them in the primary coded classifications, then operational definitions for each category were determined using previous theories. The strengths of this approach are that the existing theory can be supported or expanded. Selected theory in this kind of research can help to select appropriate research questions. Furthermore, the theory can help in predicting the interesting variables or the relationships between variables. As a result, it can be useful in the initial coding method and relationships between the codes (13). The interviews were designed Semi-structured and based on Pender's Health Promotion Model and open questions, and continued until data saturation, so that in the last four interviews, no new codes were obtained. For example, participants were asked "What are your feelings, and your experience in relation to physical activity?". Then, using the in-depth and probing questions based on responses they were asked "Please explain more about it, why and how?" to understand the depth of experience of adolescents. Then, if for example, the teenager pointed to impatience for physical activity, the expressed profound aspects were examined using probing questions, in order to find the reason of weakness, negative attitude, lack of attention to their abilities and talents, inferiority complex etc., in the creation of this impatience. If lack of motivation was the reason for lack of physical activity, the teenagers were 
often asked "What is the meaning of lack of motivation?" What obstacles make you stop your physical activity? What are the benefits of physical activity for you? How is your ability to deal with barriers to physical activity? How can the lack of proper schedule affect your physical activity? How do you plan for your physical activity? How can the expectations, encouragement and observation of important and influential people in your life affect your physical activity? What are your views regarding sports in your city and what is your attitude towards sport that you or other teenage girls do?" Each interview lasted 30 to 40 minutes. At the beginning of each interview, the aim of the study, their right to participate in the study or refusal to continue at any time during the study was explained to the subjects. Also, an informed consent was obtained from them and their data confidentiality was assured. First, the author carefully listened to interviews several times and reviewed the handwritten text several times. At the end of each interview session, at the first opportunity, the recorded data were heard by the researcher and compared to the notes and content, which were integrated and amended. The text was read several times to give a deep and correct understanding and then was broken into the smallest meaningful units (codes). The primary codes obtained from data analysis were inserted on six predetermined classifications of Pender's Health Promotion Model (perceived benefits, barriers and self-efficacy, feelings related to behavior, interpersonal and situational influencers). The four criteria of acceptability, or repeatability of portability, consistency and verifiability were used to evaluate the strength of qualitative data. The permanent and continuous involvement method relating to the research title was used to increase the acceptability of the qualitative data, so that the study was conducted over 6 months to obtain a better understanding of them. Also, code verification method was used by the subjects, so that the initial codes were controlled by the interviewee before being inserted into classifications. The reviewing method was used based on the comments of colleagues, in order to provide the ability to approve coding in the classifications of Pender's Health Promotion Model, and individual coding of interviews was performed by supervisors and advisors. Samples were chosen from different schools in different age groups, different educational levels, different educational fields and different socio-economic classes to increase the capability of data. Consistency was performed using an external monitoring method and coding of four interviews by an experienced researcher and expert in the field of qualitative research and physical activity in order to investigate discrepancies in coding and documenting the objectivity of evidence, including audio interviews, handwritten and typed texts, data analysis and review of observers to provide auditory. Verifiability was performed by specialists in physical education, health education and health promotion through returning the interview texts to the subjects and controlling the data with participants in order to review the coding and analyze a few interviews.

\section{Results}

In this study, 44 teenage girls and 6 teachers were interviewed. The mean age $\pm \mathrm{SD}$ of girls was $16.33 \pm 0.88$. Of the educational field, $6.3 \%$ were art, $25 \%$ were humanities, and $68.8 \%$ were natural sciences; $33.3 \%$ were second grade, $52.1 \%$ were third grade and $14.6 \%$ in college. Only $10 \%$ of fathers and $7 \%$ of mothers were highly educated. Of fathers, $36 \%$ were freelancers, workers and farmers and $42 \%$ of mothers were housewives. After integration and data analysis, 59 codes were extracted. These codes were inserted into six predetermined classifications of Pender's Health Promotion Model. Examples of coding and inserting them in classifications are given in Table 1.

\subsection{Perceived benefits}

Teenagers' prediction of positive results of physical activity includes: 1) improvement in appearance and fitness, 2) improvement in different organs, 3) feelings of joy, happiness and peace, 4. increased resistance to stress, 5) reduced anxiety and stress, 6) increased self-confidence, 7) improved memory and increased power of learning and concentration, 8) socialization, 9) respect for the rules, 10) regard for collective interests and strengthening of team and group spirit, 11) better use of free time, 12) more comfortable sleep, 13) longer life. One of the students commented, "Young people and teenagers who do exercise seldom use drugs such as opium or cigarettes, because they spend their free time in sport. Many of those who were addicted could easily quit through exercise, an example in our family was a cousin who stopped his addiction more comfortably by doing exercise every day, and now it has been 6 years since his addiction (Participant no. 34)". One of the physical education teachers commented about the benefits of exercise: "Withdrawal and isolation can be seen in this age group, according to my experience during teaching years, I've seen students who were weak in communicating with others. Exercise and participating in sports venues would strengthen the ability to communicate with others. Group games make teenagers leave their shame and prepare themselves to enter into society (P43)".

\subsection{Perceived barriers}

More teens recognize the real or perceived barriers to physical activity as: 1) sports are time-consuming, 2) damage to their body after exercise, 3) exercise-induced fatigue, 4) lack of self-confidence for exercise, 5) lack of skills 
needed for exercise, 6) lack of planning ability for exercise, 7) lack of access to appropriate sports venues, 8) high cost of equipment of favorite sport, 9) high cost of registration fee of sports clubs, 10) lack of safe places for exercise, 11) attraction of information and communication technology such as TV, satellite, computer or tablet games, internet, social networks, Viber, WhatsApp, Telegram, Line etc., 12) lack of adequate support from the community for exercise, 13) The high amount of homework. One of the students commented, "I spent much of my time on mobile games and social networks during the day, then I get tired and I like to sleep, then I have to study, so there's no time for exercise (P9). "Another student said, "Lack of time is a factor that discourages me from exercise and in my spare time I excessively play computer games or get involved in social networking and spend all my time on them. But I know how harmful this is to my health, but when I sit behind my laptop, I cannot get up, and suddenly I find out that I regularly spend three hours there. Sometimes I don't see enough weight difference for the exercise, and this makes me disappointed and I stop doing exercise. The amount of school lessons are too much, it would be better if the sport hour at school was more (P23). "Other participants revealed, "I would love to go to gym clubs, but it costs so much, and don't know much about aerobics and Zumba rules. As soon as learn a sequence of exercises, the next move begins and I cannot synchronize myself. Once, I put too much pressure on myself until I had constant knee pain. The club is too far away from our home, it would be better if we had a sports hall at school (P12)."

Table 1. Example of coding the interviews of teenage girls and inserting them in the classification of Pender's Health Promotion Model

\begin{tabular}{|l|l|l|}
\hline Classifications & Codes & Comments of teachers and students \\
\hline $\begin{array}{l}\text { Perceived } \\
\text { benefits }\end{array}$ & $\begin{array}{l}\text { Predicted positive results of physical } \\
\text { activity }\end{array}$ & $\begin{array}{l}\text { "In the past I felt I could learn my lessons better } \\
\text { after exercise, and now I feel stupid that I gave } \\
\text { up exercise " } \\
\text { "Since I started my exercise, my body looks } \\
\text { better and my back pain has gone" }\end{array}$ \\
\hline $\begin{array}{l}\text { Perceived } \\
\text { barriers }\end{array}$ & $\begin{array}{l}\text { Conceived or real barriers resulting from } \\
\text { the exercise. }\end{array}$ & $\begin{array}{l}\text { "there is so much homework that we can't find } \\
\text { free time to exercise" } \\
\text { Directors and administrative staffs of schools do } \\
\text { not give importance to physical education." }\end{array}$ \\
\hline $\begin{array}{l}\text { Perceived self- } \\
\text { efficacy }\end{array}$ & $\begin{array}{l}\text { Judgment about one's own ability to } \\
\text { organize and do physical activity }\end{array}$ & $\begin{array}{l}\text { Since I found an online sports telegram group, I } \\
\text { committed myself to do the exercises everyday } \\
\text { through the online posts and training movies" }\end{array}$ \\
\hline $\begin{array}{l}\text { Feelings related } \\
\text { to behavior }\end{array}$ & $\begin{array}{l}\text { Positive and negative emotions before, } \\
\text { during and after physical activity }\end{array}$ & $\begin{array}{l}\text { I feel good when I exercise, I feel happy and } \\
\text { cheerful and I behave better and become kinder. }\end{array}$ \\
\hline $\begin{array}{l}\text { Interpersonal } \\
\text { influencers }\end{array}$ & $\begin{array}{l}\text { Norms, supports and patterns } \\
\text { "When I get so lazy, my family notify me, } \\
\text { sometimes I exercise at home with my mother } \\
\text { and I play with my sister." }\end{array}$ \\
\hline $\begin{array}{l}\text { Situational } \\
\text { influencers }\end{array}$ & $\begin{array}{l}\text { The subject's perceptions of facilitators, } \\
\text { inhibitors and available choices and } \\
\text { aesthetic properties of the environment for } \\
\text { physical activity }\end{array}$ & $\begin{array}{l}\text { "I think if there was more facility in our city, of } \\
\text { course, we would be more eager to exercise, but } \\
\text { because there are no facilities, we lose that little } \\
\text { enthusiasm " }\end{array}$ \\
\hline
\end{tabular}

\subsection{The perceived self-efficacy}

Teenagers claimed that they have the ability to organize and perform physical activities even if they have other things to do (such as homework, traveling and attending parties). Also, with lack of sports facilities, or if their family and friends prevent them from doing exercise, they still try to do exercise during the week, and have required physical activity. Some teenagers complained of not being able to overcome laziness, and others mentioned "not having a good coach" and "inadequate skills" as the reasons for their inability to do effective exercise. Others sometimes mentioned inappropriate mental condition as a reason which reduces their ability to exercise. But some of the teenagers claimed that they can continue to exercise even in inclement weather conditions, while others said fatigue and pain caused by exercise had failed them. Some of them said that they have the ability to use information and communication facilities (Internet, CDs, etc.) to learn exercises, and can properly use available equipment and sports facilities; but some of them said that they are not motivated to exercise when they are alone. In contrast, others claimed to have the ability to use new information and communication technology to increase their knowledge and motivate by themselves or with their friends. One of the students said, "I try to do exercise when I have more energy such during evenings, and I write down my exercise program or my weight loss in order to be 
more motivated. Sometimes we mention high-calorie foods that we ate with friends in the telegram, and we report our walking or jogging time using SMS to make each other more motivated (P14). "A teenage girl said, "I try to walk from school or remedial classes to home. I do exercise at home with music. We play games when I go on a picnic with the family. We set a time to play volleyball with my friends (P18). "Another student said, "My school counselor says that I should exercise three days a week and those who did, were successful in education and exams and also able to learn better; and indeed, this advice had a great influence on my progress (P17)." Other participants said, "I choose activities that do not require much skill, like walking, climbing stairs or jogging. I usually exercise with friends who have the same sport skills as me. However, I try to exercise and learn skills from friends who learn well at the sports club. I try to exercise in groups because team sports are much happier (P25). "

\subsection{Feelings related to behavior}

Positive and negative emotions created before, during and after physical activity can be effective on self-efficacy for physical activity of adolescents, the adolescent may have a feeling of joy, happiness and lightness, or attractiveness, feeling fatigued or short of breath after exercise or have the stress of not doing homework. Teen girls said, "When I do exercise, my attention goes away from domestic problems and issues, and it can be an opportunity to revitalize mentally and to get rid of psychological pressure (P17)" and "When I do exercise I feel good, happy, and cheerful, my behavior is better and I become more kind to everyone (P33)." One of them said, "When I do exercise I feel a little tired and short of breath, but a good feeling takes the place of fatigue (P15)." Another student said, "Fatigue, sweating and bad smell are unpleasant feelings that I have after exercise (P19)."

\subsection{Interpersonal influencers}

Adolescents claimed the expectations and support of family, teachers, family members and close friends, from them observing their behavior as well as the recommendations of a popular athlete are the factors affecting their performance in physical activity. One of the participants said, "A member of our country's national volleyball team, called Seyed Mohammad Mousavi had a big impact on me, I would love to be like him (P12)." Other participants said, "My sister and brother encourage me so much to do sport, but school authorities are not so supportive (P16)." And another added, "I love your gym teacher, she was really very helpful for my success in Tae Kwon Do, I would love to see my family be proud of me (P11)." and "My mother is an athlete, she encourages me to go to the sports club with her (P14)."

\subsection{Situational influencers}

The understanding and knowledge of teenagers about the facilitators, barriers, available choices and aesthetic characteristics of their environment for physical activity include: 1) supportive rules and policies of school for exercise, 2) having a suitable place in the educational environment, 3) having a suitable place and atmosphere at home, 4) attitudes of community towards sport girls, 5) personal attitude towards teenage girls exercising, 6) ability to choose any favorite sport, 7) easy access to playgrounds, parks and sports venues nearby, 8) safe places to walk and exercise at different times of the day, and 9) sufficiency of favorite sports accessories. A teenage girl disclosed, "Our school has no sport hall to raise motivation, school authorities can bring bikes to school, but they do not care about it, the sports lessons are always the least important lesson (P14)." One of them said, "We do not have good facilities for sports in our city, and if we want to exercise early in the morning, everyone tries to watch us like we are doing something wrong, people in our culture are not ready to see girls freely riding a bike or jogging in sport cloths (P25)." Another participant said, "I think if we had more sports equipment and parks for women, certainly our passion for the sport would be more (P10)." Another student said, "Our sports environment is not suitable, pools are small, gym halls have no heaters or air conditioning system, and we do not feel safe (P7)."

\section{Discussion}

The findings of this study showed that promotion of physical activity among teenage girls can be explained using Pender's Health Promotion model, influenced by the perceived benefits, perceived barriers, self-efficacy, feelings related to behavior, interpersonal and situational influencers. The results showed that perceived barriers and situational influencers are effective in decreasing levels of physical activity among teenage girls, and high selfefficacy has a more important role than other classifications in the promotion of physical activity in teenagers. The results of Aghamolaie et al (14) showed that perceived barriers can affect the high perceived benefits to exercise; also, self-efficacy is not only directly effective in increasing physical activity, but also has indirect effect through reducing perceived barriers. The role of situational influencers on understanding the behavioral facilitators or barriers in our study was consistent with the results of a Mohebbi et al. study about the effect of situational influencers on healthy nutrition (15). The 'perceived benefits' means the individuals' perceptions on the benefits of 
a behavior that directly and indirectly has influence on the behavior (16). Accordingly, teenage girls who understand the psychological and social benefits associated with physical activity behavior, showed a greater tendency toward physical activities. Previous researches also showed that by increasing the understanding of the benefits of physical activity, this behavior would be improved. Colette and Terry also reported the promotion of physical and mental health as the most important benefit of physical activity in healthy populations $(17,18)$. In this study, the most important perceived benefits were the fitness, happiness, joy and stress reduction; this result was consistent with other studies $(19,14)$. The perceived barriers are the real, tangible or intellectual obstacles that a person understands to do the desired behavior (16). In this study, factors such as 'lack of time' are the most important perceived barriers for physical activity; this result was also consistent with the results of other studies (25-19). One of the main reasons for lack of time mentioned by teenagers was the attraction of information and communication technology. What happened in the contemporary industrial life is going toward the sedentary life, and unfortunately today, physical activity is limited in childhood and adolescence because of the proliferation of virtual games and computers. The results of Baheiraei et al. accepted the role of information and communication technology in the sedentary lifestyle of adolescents (26). The perceived self-efficacy means the trust in the ability to successfully perform a new health behavior or giving up an unhealthy behavior (27). In the present study the ability to overcome the sense of laziness, fatigue and excessive preoccupation were the most important factors expressed by adolescents, which shows high efficacy in those teenage girls who had regular physical activity. This study showed the association the importance of perceived self-efficacy and regular physical activity; this result corresponds with the findings of the study of Wallace and Rovniak $(29,28,14)$. One of the major issues that was expressed by a number of teenagers was the ability to use information and communication facilities (Internet, CDs, etc.) to learn and perform the exercises. This perceived factor by teenage girls is the innovative aspect of this study. A virtual world can create interest and ability to physical activities in many ways, and can draw a good image of sport among the audience, and create motivation and habit to exercise. Thus, according to Bandura's findings, the most robust factor in predicting behavioral change is self- efficacy, and usually those who show the greatest behavioral change have the higher self-efficacy level to do a particular behavior (30). Interpersonal influencer means to recognize the factors related to a person's behavior, beliefs or attitudes. Effective interpersonal factors include the expectations of other persons and social support through incentives or emotional tools and modeling and observational learning by observing a certain behavior from others (31). In this study, the most effective influencers and encouragers to have regular physical activity behavior on the interpersonal norms and social support include family, friends and family members and sport teachers, respectively; in the interpersonal modelling, the family, the national team members, friends and family members were mentioned as the models to do physical activities by adolescents. In this study, adolescent girls who had the support of family members and teachers had more regular physical activity. This research provided a better understanding of how family has influence on the formation of the physical activity behavior of teenage girls, which is consistent with the results of other studies $(23,32,33)$. Identifying the role of the family in this regard, can help in designing more effective family-based interventions, and also help health professionals and physical education teachers (33). According to the results of the present study, one of the most influential factors in regular physical activity is the role of physical education teachers and administrators expressed by participants, which is similar to results of other studies (34). Primarily, the responsibility for education programs for students in schools is the collective and group work in which physical education teachers also have a decisive role. It is expected that school administrators as well as the members of training teams provide a favorable environment for optimal performance of physical education in schools. The feelings associated with the activity, and emotional condition that occurred before, during, and after a certain behavior can be stored in the memory and result in the replication or leaving a behavior (16). Pleasant and unpleasant feelings associated with physical activity behavior expressed by teenagers, confirmed the results of other studies. Robins et al., in a study entitled "Moving toward increasing physical activity of girls", stated that $70 \%$ of people are at risk of leaving physical activity behavior because of the consequences of such activities as fatigue, intolerance and pain. So, a slow start creates a pleasant feeling and is associated with longterm persistence (35). Situational influencers include the person's perception and cognition of a certain situation or context which can be a facilitator or barrier to a behavior. The pervasive factor in available choices includes the specifications of demands and aesthetic properties of the environment in which the suggested behavior occurs (30). In this study, teenage girls mentioned situational influencers as the facilitators or barriers of physical activity behavior. The results of similar studies $(15,36)$ also indicated that the individuals become more attracted to situations and areas where they feel more consistency, relevance, health and safety, and they do not have a good performance in environments that induce the feeling of inconsistency, irrelevancy and lack of safety. Based on these results, it can be concluded that the influencers can have direct and indirect effects on health behavior. Therefore, the situational effects may be an important key to the development of new and more effective strategies to facilitate the acquisition and retention of health promotion. 


\section{Conclusions}

Understanding the attitudes and behavior of teenage girls in terms of physical activities, and recognizing the cultural-social-psychological factors affecting this behavior and explaining the barriers and facilitators related to physical activity in girls can help the researchers and decision-makers to design interventions related to the improvement of the knowledge, attitudes and skills, and can result in reducing the burden of diseases associated with physical inactivity in this gender and age group.

\section{Acknowledgments:}

This paper describes part of the results of research performed for a $\mathrm{PhD}$ degree in health education and health promotion. We hereby thank all people who contributed to this research. The authors would like to express their appreciation to the Deputy of Research of Tehran University of Medical Sciences for their support and funding of this project. We would also like to thank the Education Office of Minoodasht city for their cooperation.

\section{Conflict of Interest:}

There is no conflict of interest to be declared.

\section{Authors' contributions:}

All authors contributed to this project and article equally. All authors read and approved the final manuscript.

\section{References:}

1) WHO. Sedentary lifestyle a global public health problem. Geneva: WHO; 2002. Available from: http://www.who.int/dietphysicalactivity/factsheet_inactivity/en/.

2) Khang YH, Lynch JW, Kaplan GA. Health inequalities in Korea: age-and sex-specific educational differences in the 10 leading causes of death. Int J Epidemiol. 2004; 33(2): 299-308. doi: 10.1093/ije/dyg244. PMID: 15082630.

3) Hallal PC, Andersen LB, Bull FC, Guthold R, Haskell W, Ekelund U, et al. Global physical activity levels: surveillance progress, pitfalls, and prospects. Lancet. 2012; 380(9838): 247-57. doi: 10.1016/S01406736(12)60646-1. PMID: 22818937.

4) Kohl HW, Craig CL, Lambert EV, Inoue S, Alkandari JR, Leetongin G, et al. The pandemic of physical inactivity: global action for public health. Lancet. 2012; 380(9838): 294-305. doi: 10.1016/S01406736(12)60898-8. PMID: 22818941.

5) Mounesan L, Sepidarkish M, Hosseini H, Ahmadi A, Ardalan G, Kelishadi R, et al. Policy Brief for Promoting Physical Activity among Iranian Adolescents. Journal of Isfahan Medical School. 2013; 31(233): 510-20.

6) Dastjerdi R, Eftekhar Ardebili H, Poorreza A, Assasi N, Golestan B. Assessment of the stage of change in physical activity among high school girls. SJSPH. 2004; 2(2): 25-34.

7) Kelishadi R, Kahbazi M, Rabiei K, Heidari S, Doreh F, Baghaie A. Physical activity level among children of markazi and Isfahan provinces (2000). AMUJ. 2004: 7(1): 26-33.

8) Motameni A, Hemmati A. Identifying and prioritizing the barriers for women's sports activities. Journal of Sport Management Review. 2014; 6(24): 111-30.

9) Taymoori P, Lubans DR. Mediators of behavior change in two tailored physical activity interventions for adolescent girls. Psychology of Sport and Exercise. 2008; 9(5): 605-19. doi: 10.1016/j.psychsport.2007.09.001.

10) Russell J, Rowan B, Fox KR, Cartwright K, Page AS, Thompson JL. Friendship groups and physical activity: qualitative findings on how physical activity is initiated and maintained among 10-11 year old children. International Journal of Behavioral Nutrition and Physical Activity. 2009; 6(1): 1. doi: 10.1186/1479-5868-6-4.

11) Thomas J, Silverman S, Nelson J. Research Methods in Physical Activity. 7th Edition. Human kinetics; 2015.

12) Hsieh HF, Shannon SE. Three approaches to qualitative content analysis. Qual Health Res. 2005; 15(9): 1277-88. doi: 10.1177/1049732305276687. PMID: 16204405.

13) Mehrdad N, Oskouie F, Seyed Fatemi N. Qualitative Content Analysis. Tehran: Boshra; 2013.

14) Agha Molaei T, Tavafian SAS, Hasani L. Exercise self-efficacy, exercise perceived benefits and barriers among students in Hormozgan University of Medical Sciences. J Iran epidemiology. 2009; 4(3,4): 9. 
15) Mohebbi S, Azadbakht L, Feyzi A, Sharifirad Gh, Hozoori M. An Assessment of the Correlation between Nutritional Self-management and Health Promotion Model Constructs in Women with Metabolic Syndrome, 2012. Qom University of Medical Sciences Journal. 2013; 7(5): 42-52.

16) Pender NJ, Murdaugh CL, Parsons MA. Health promotion in nursing practice. 4th ed. Prentice Hall: Upper Saddle River; 2002.

17) Collette M, Godin G, Bradet R, Gionet NJ. Active living in communities: understanding the intention to take up physical activity as an everyday way of life. Can J Public Health. 1994; 85(6): 418-21. PMID: 7895218.

18) Terry DJ, O'Leary JE. The theory of planned behaviour: The effects of perceived behavioural control and self - efficacy. Br J Soc Psychol. 1995; 34(2): 199-220. PMID: 7620846.

19) Tzormpatzakis N, Sleap M. Participation in physical activity and exercise in Greece: a systematic literature review. Int J Public Health. 2007; 52(6): 360-71. doi: 10.1007/s00038-007-6118-6. PMID: 18368999.

20) de Assis MA, de Mello MF, Scorza FA, Cadrobbi MP, Schooedl AF, Gomes da Silva S. Evaluation of physical activity habits in patients with posttraumatic stress disorder. Clinics. 2008; 63(4): 473-8. doi: 10.1590/S1807-59322008000400010. PMID: 18719757, PMCID: PMC2664122.

21) Ball K, Salmon J, Giles-Corti B, Crawford D. How can socio-economic differences in physical activity among women be explained? A qualitative study. Women \& health. 2006; 43(1): 93-113. doi: 10.1300/J013v43n01_06.

22) Carron AV, Hausenblas HA, Estabrooks PA. The psychology of physical activity. McGraw-Hill Companies; 2003.

23) Downs DS, Hausenblas HA. Elicitation studies and the theory of planned behavior: a systematic review of exercise beliefs. Psychology of sport and exercise. 2005; 6(1): 1-31. doi: 10.1016/j.psychsport.2003.08.001.

24) Foley L, Prapavessis H, Maddison R, Burke SH, McGowan E, illanders L. Predicting physical activity intention and behavior in school-age children. Pediatric Exercise Science. 2008; 20(3): 342-56. doi: 10.1123/pes.20.3.34.

25) Tondnevis F. Exercise position in Iranian woman leisure time. Harekat. 2002; 12: 87-104.

26) Baheiraei A, Hamzehgardeshi Z, Mohammadi MR, Mohammadi E, Vedadhir AA. Expert approaches to promote adolescent physical activity in iran: development of the promoting strategies using the nominal group technique meeting. J Phys Act Health. 2014; 11(5). doi: 10.1123/jpah.2012-0032. PMID: 23676297.

27) Norman P, Boer H, Seydel ER. Protection motivation theory. Practice with Social Cognition Models. Open University Press. Maidenhead. 2005: 81-126.

28) Rovniak LS, Anderson ES, Winett RA, Stephens RS. Social cognitive determinants of physical activity in young adults: a prospective structural equation analysis. Annals of Behavioral Medicine. 2002; 24(2): 14956. doi: 10.1207/S15324796ABM2402_12.

29) Wallace LS, Buckworth J, Kirby TE, Sherman WM. Characteristics of exercise behavior among college students: application of social cognitive theory to predicting stage of change. Preventive medicine. 2000; 31(5): 494-505. doi: 10.1006/pmed.2000.0736.

30) Bandura A. Self-efficacy: toward a unifying theory of behavioral change. Psychological review. 1977; 84(2): 191.

31) Dehdari T, Ramezankhani A, Zarghi A. Principles of health promotion. Tehran: Nazari Publication; 2010. doi: 10.1037/0033-295X.84.2.191.

32) Arizi F, Vahida F, Parsamehr M. The study of social support effect on females participation at physical activities. Olympic. 2006; 14(1): 77-86.

33) Hosseini SV, Anoosheh M, Abbaszadeh A, Ehsani M. female adolescents' and their parents' perception of family role in Forming girls' physical activity behavior. Develompent and Motor Lerning (Harkat). 2013; (13): 61-77.

34) Shabani B, Erfani GR, Eshragi N. Evaluation of the factors affecting the quality of the physical education in secondary schools From the perspective of sports teachers. Research in sports science. 2008; 1(5): 14356.

35) Robbins LB, Gretebeck KA, Kazanis AS, Pender NJ. Girls on the move program to increase physical activity participation. Nursing research. 2006; 55(3): 206-16. doi: 10.1097/00006199-200605000-00007. PMID: 16708045.

36) Dehdari T, Rahimi T, Aryaeian N, Gohari MR. Effect of nutrition education intervention based on Pender's Health Promotion Model in improving the frequency and nutrient intake of breakfast consumption among female Iranian students. Public health nutrition. 2014; 17(03): 657-66. doi: 10.1017/S1368980013000049. 